medium's muscular processes. This fact alone seems to rule out confederacy.

When the above relations had been recognised, arrangements were made for automatically recording the motions of the medium's chest, at the same time as the infra-red absorptions. A scale of seconds was placed on each record, and by an obvious electrical method, synchronous signalswere made on each, so as to afford a time-origin from which to measure the frequencies. Sample records (Figs. 1 and 2) are here reproduced from MM. Osty's memoir. The absorption lasts for 7 seconds, and oscillates with a frequency of 5 per second. At the same time the breathing is at the rate of 2.5 per second. These are the figures given by MM. Osty. They can be approximately verified from the half-tone blocks in their publication, though the individual oscillations are not invariably well resolved in the reproduction.

In attempting to estimate the work of MM. Osty, we must consider in what directions there might be a chance of shaking their evidence. Mere topics of prejudice should be avoided. It has often been suggested that Rudi Schneider makes use of confederates, either secretly introduced, or openly present in the guise of sitters. Will it help us to assume that he did so in this case? The answer appears to be in the negative. It is not apparent how a confederate could assist in producing the rhythmic obscuration, in time with Rudi Schneider's breathing. When it has been shown that an assistant, working without disguise, can do this, the hypothesis of confederacy will require closer examination.

Again, it has often been argued that Rudi Schneider can get an arm free in spite of the apparent control. This hypothesis has the same weakness as the previous one. How can he use the (hypothetical) free arm to produce the effects?
No answer to these questions has so far been forthcoming.

Lastly, is it possible that MM. Osty were deceived, and that the records which they imagined they had obtained on their photographic drums were really prepared independently by Schneider or some confederate of his, and palmed off on MIM. Osty before development in substitution for their own records? It must be remembered that the relation between Schneider's breathing and the infra-red intensity was first noticed visually by the motion of the galvanometer spot, before it had been recorded photographically ; so that this hypothesis also seems to fail.

The value of the evidence of MM. Osty, or of any other witnesses, must depend on what view is taken of their good faith. This in turn must depend on general reputation, on internal consistency and coherence of evidence, and on the possible motives for deception.

It would be of the greatest importance for the work to be independently repeated in some other laboratory. Unfortunately, Rudi Schneider's powers are apparently failing. Some have considered this fact to be in itself suspicious. It must be remembered, however, that even at their best the phenomena were sporadic, with many blank sittings interspersed. In any event, it is not clear why the trick, if trick it was, should not continue to be played as long as it is profitable. On the alternative hypothesis, it seems not particularly unlikely that exceptional natural powers of this kind might pass off with time, as do, for example, the powers of 'calculating boys'.

Anyone who sees his way to a normal explanation for these effects would be doing a service to the cause of truth by setting up the apparatus and producing graphs similar to those published by MM. Osty.

\title{
Obituary
}

\section{Prof. A. N. Meldrum}

$\mathrm{B}^{\mathrm{Y}}$ the death of Prof. Andrew Norman Meldrum on March 12 the activities of one of the best-informed writers on historical matters relating to eighteenth and nineteenth century chemistry have come to a close. The history of the greater movements in the progress of theoretical chemistry formed a favourite branch of study and research, and from an early period Prof. Meldrum's attention was directed to the subject of the atomic theory, in connexion with which he published, so early as 1904, a thoughtful and elaborate monograph on "Avogadro and Dalton: The Standing in Chemistry of their Hypotheses". This was followed by a series of papers "On the Development of the Atomic Theory", contributed to the Literary and Philosophical Society of Manchester in 1909-11, and by a pamphlet with the same title published in India in 1920. He was engaged during a number of years upon an intensive study of the works of
Lavoisier and his contemporaries. In this period he accumulated a large amount of material for the production of the successive lengthy papers that appeared between 1924 and 1934, dealing with Lavoisier's part in "The Eighteenth Century Revolution in Science", with his historic "Three Notes on Combustion : 1772", and with his "Early Work in Science: 1763-1771". Besides these valuable papers, Meldrum contributed one of the three special commemorative addresses on Joseph Priestley that were read before the Chemical Society in April 1933, on the occasion of the bicentenary of that philosopher.

In his published historical work, Meldrum appears as a close student as well as a keen and, at times, outspoken critic. He was not willing to accept, without verification, the statements made by compilers, but was in the habit of making it a point to obtain first-hand information from original sources. In the case of his researches into Lavoisier's work, this usage involved the making 
of extensive inquiries in Paris, not only by correspondence but also by personal visitation, and in this way he ensured the authenticity of his own statements. After the publication, so recently as last January, of his concluding Lavoisier paper, he had begun a study of the life and work of Black and was actively engaged a few days before his unexpected death in a minute examination of the contemporary and subsequent literature relating to Black's discoveries.

Meldrum studied chemistry with Japp at Aberdeen and took his D.Sc. degree at the University there in 1904, his graduation thesis being the Avogadro-Dalton monograph already mentioned. Afterwards he carried on research work in organic and in physical chemistry in collaboration with Japp, Perkin, jun., and others. In 1912, he was appointed to the professorship of chemistry in the Madhavlal Ranchhodal Science Institute, Ahmedabad, from which he was transferred later to the Royal Institute of Science, Bombay, both of these institutions being affiliated to the University of Bombay. From his post in the latter he retired in 1931 and resided thereafter in Edinburgh. $\mathrm{He}$ is survived by his widow and two daughters.

\section{Mr. R. LL. Jones Llewellyy}

Mr. Richard Llewellyn Jones Llewellyn, who died suddenly on April 19, had made a lifelong study of rheumatism and allied disorders, on which he was regarded as an eminent authority. The son of Surgeon-Major Morris Jones of Aberystwyth, he assumed the name of Llewellyn in 1911 on his marriage to the Hon. Mrs. Crosse of Hulbertson, only child of the fourth Lord Headley.

Llewellyn had been president of the Balneological and Climatological Section of the Royal Society of Medicine; consulting physician to the National Hospital for Rheumatism at Bath; member of the conference on chronic arthritis convened by the Medical Research Council; chairman of the Medical Committee of the National Campaign for the Prevention and Relief of Heart Disease in Children; and vice-president of the British Committee on Rheumatism, International Society of Medical Hydrology. He was also a member of the Board of Medicine, Welsh National School of Medicine; a fellow of the Royal Society of Medicine, of the Hunterian Society and of the Royal Meteorological Society.

In his researches into rheumatic diseases, Llewellyn was greatly helped by his brother, A. Bassett Jones.

Llewellyn was the author of several books and articles on rheumatism, arthritis, fibrositis and gout. At the time of his death he was engaged on a study of the relations of rheumatism to the absence of sunshine and the consequent failure of the skin to mobilise the chemical antecedents of the endocrines, a new view which has attracted considerable attention in the United States.

Llewellyn had been a member of the central appeals tribunal of the Ministry of Pensions, and was widely quoted as the author of "Malingering or the Simulation of Disease" (1917) and "Pensions and the Principles of their Evaluation" (1919). Llewellyn's style was picturesque and vivid; his conversation was arresting, original and spiced by shrewdness and humour.

\section{Mr. C. E. Borcharevink}

Carsten Egeberg Borchgrevink, whose death at Oslo is announced, was born in that town, then Kristiania, in 1864. After an education in Norway and Saxony, he went to Australia in 1888 and spent some years in Queensland and New South Wales, first as a land surveyor and later as a teacher of modern languages and natural science.

When in 1894 Svend Foyn sent a ship to the Antarctic under the command of L. Kristensen and H. J. Bull to explore whaling possibilities, Borchgrevink signed on as an ordinary seaman, having failed to get accepted as a passenger. The ship reached lat. $74^{\circ} \mathrm{S}$. in the Ross Sea and Borchgrevink in landing at Cape Adare was one of the first to set foot on the Antarctic continent. $\mathrm{He}$ also was the discoverer of plant life within the Antarctic Circle.

Returning to Europe, Borchgrevink tried in vain to equip a trading expedition to South Victoria Land to search for guano. In 1898, however, he induced Sir George Newnes to fit out the Southern Cross (formerly the Norwegian whaler Pollux) for a scientific expedition to the Ross Sea, the first since that of Sir James C. Ross in 1841. A wintering was made at Cape Adare where many valuable observations were made by L. Bernacchi, N. Hanson and others, and on the return of the ship in spring a voyage was made south to the Barrier face. Borchgrevink and W. Colbeck travelled over the Barrier to lat. $78^{\circ} 50^{\prime} \mathrm{S}$., at that time a southern record.

In 1902 Borchgrevink investigated volcanic conditions in the West Indies on behalf of the National Geographic Society and in the later years of his life was curator of the Tömte Biological Station in Norway. He received the Patron's medal of the Royal Geographical Society in 1930, and a medal of the Royal Scottish Geographical Society in 1900. His chief publications were "First on the Antarctic Continent" (1901), "Das Festland am Südpol" (1905) and "The Game of Norway" (1920-25).

R. N. R. B.

WE regret to announce the following deaths :

Dr. Angel Gallardo, formerly Argentine Minister for Foreign Affairs, rector of the University of Buenos Aires since 1932, and president of the Academy of Sciences in Buenos Aires since 1927, aged sixty-six years.

Prof. C. W. Rolfe, emeritus professor of geology in the University of Illinois, an authority on the geology of Illinois, on April 6, aged eighty-three years. 